\title{
Distribution of energy intake throughout the day and weight gain: a population-based cohort study in Spain
}

\author{
Ygor Hermengildo ${ }^{1,2}$, Esther López-García ${ }^{1}$, Esther García-Esquinas ${ }^{1}$, Raúl F. Pérez-Tasigchana ${ }^{1}$, \\ Fernando Rodríguez-Artalejo ${ }^{1}$ and Pilar Guallar-Castillón ${ }^{1 *}$ \\ ${ }^{1}$ Department of Preventive Medicine and Public Health, Universidad Autónoma de Madrid/IdiPaz and CIBER of \\ Epidemiology and Public Health (CIBERESP), Madrid 28029, Spain \\ ${ }^{2}$ Hospital Universitario 12 de Octubre, Madrid 28041, Spain
}

(Submitted 19 October 2015 - Final revision received 12 February 2016 - Accepted 16 February 2016 - First published online 5 April 2016)

\section{Abstract}

Experimental research suggests that food timing is associated with weight regulation. However, the association between the distribution of energy intake (EI) throughout the day and weight gain in the population is uncertain. A cohort of 4243 individuals ( $49 \cdot 9 \%$ men, $50 \cdot 1 \%$ women) aged $\geq 18$ years was selected in 2008-2010 and followed-up through 2012. At baseline, food consumption for a typical week in the previous year was collected with a validated dietary history, and EI was assessed at six eating occasions: breakfast, mid-morning meal, lunch, mid-afternoon meal, dinner and snacking (at any other moment). Individuals were classified into sex-specific quartiles of \%EI for each eating occasion. The cutoff points for increasing quartiles of \%EI at lunch were $34 \cdot 4,40 \cdot 8$ and $47 \cdot 7 \%$ in men and $33 \cdot 2,39 \cdot 4$ and $46 \cdot 1 \%$ in women. Weight was selfreported at baseline and at the end of follow-up. During a 3.5-year follow-up, $16.3 \%$ of study participants gained $>3 \mathrm{~kg}$. Compared with those in the lowest quartile of \%EI at lunch, the multivariate OR of gaining $>3 \mathrm{~kg}$ was $0.79(95 \% \mathrm{CI} 0.63,0.99)$ in the second quartile, 0.82 (95\% CI 0.64 , $1.04)$ in the third quartile and $0.62(95 \%$ CI $0.47,0.80)$ in the highest quartile $\left(P_{\text {trend: }}: 0.001\right)$. The association was stronger among women and those with overweight or obesity. No association was found between the \%EI at the rest of the eating occasions and weight gain. In conclusion, a higher \%EI at lunch was associated with a lower risk of weight gain; this may help weight control through the appropriate distribution of daily EI.

Key words: Energy intake: Weight gain: Circadian timing: Cohort studies: Spain

Weight gain results from an imbalance between energy intake (EI) and energy expenditure. However, it has been recently postulated that factors beyond the net energy balance may also contribute to weight regulation. Among these factors are differences in the metabolic response between proteins, carbohydrates and fats ${ }^{(1)}$ as well as the circadian rhythm ${ }^{(2)}$, light exposure $^{(3)}$ and the timing of EI throughout the day ${ }^{(2,4)}$.

Experimental research on animals suggests that the timing of feeding may be associated with weight gain. Nocturnal mice fed for 6 weeks with a high-fat diet during the 12-h light phase gained significantly more weight than mice fed during the $12-\mathrm{h}$ dark phase, despite consuming an equivalent amount of energy (mice fed during the light phase had a higher fat percentage of 7.8). Therefore, simply modifying the time of feeding can affect body weight ${ }^{(5)}$.

In humans, clinical trials with dietary interventions among overweight patients suggest that the distribution of EI throughout the day and the timing of meals may affect weight loss. Among ninety-three women with metabolic syndrome who were randomised to an isoenergetic 'breakfast' $(2929 \mathrm{~kJ} / 700 \mathrm{kcal}$ breakfast, $2092 \mathrm{~kJ} / 500 \mathrm{kcal}$ lunch and $837 \mathrm{~kJ} / 200 \mathrm{kcal}$ dinner) or 'dinner' group $(837 \mathrm{~kJ} / 200 \mathrm{kcal}$ breakfast, $2092 \mathrm{~kJ} / 500 \mathrm{kcal}$ lunch and $2929 \mathrm{~kJ} / 700 \mathrm{kcal}$ dinner) during 12 weeks, those in the 'breakfast' group showed greater weight loss and waist circumference reduction. Moreover, BMI was significantly different between the groups, with a $10 \%$ reduction in the 'breakfast' group and only a $5 \%$ reduction in the 'dinner' group ${ }^{(6)}$. In another study with a $20-$ week dietary intervention in obese individuals, late lunch eaters (who had lunch around 15.00 hours) lost less weight and displayed a slower weight-loss rate than early lunch eaters (with lunch around 13.00 hours). Late eaters only lost $9 \cdot 0$ (SD 7.1)\% of their initial weight, whereas early eaters lost 11.3 (SD 5.8) \%. In this study, EI, dietary composition, estimated energy expenditure, appetite hormones and sleep duration were similar in late and early lunch eaters ${ }^{(7)}$.

In recent years, some studies have focused on the association between food timing and the metabolic syndrome ${ }^{(8)}$, hyperten$\operatorname{sion}^{(9)}$ or diabetes ${ }^{(10)}$. However, the association between the daily distribution of EI and weight gain is still uncertain. To our knowledge, this is the first study to evaluate the role of the distribution of EI throughout the day on weight gain in adults from the general population.

\footnotetext{
Abbreviations: EI, energy intake; PA, physical activity; MEDAS, Mediterranean Diet Adherence Screener.
} 


\section{Methods}

\section{Study design and participants}

Data were obtained from the ENRICA study (Study on Nutrition and Cardiovascular Risk in Spain; Estudio de Nutrición y RIesgo CArdiovascular en España), methods of which have been reported elsewhere ${ }^{(11,12)}$. In brief, this study was conducted among 12883 persons representative of the non-institutionalised population of Spain aged $\geq 18$ years. Participants were selected in 2008-2010 by stratified cluster sampling. First, the sample was stratified by province and size of the municipality. Second, clusters were chosen randomly in two stages: municipalities and census sections. Finally, the households within each section were selected by random telephone dialing; subjects in the households were chosen proportionally to the sex and age distribution of the Spanish population. Information was collected in three stages: a phone interview to collect information on health status, lifestyle, morbidity and healthcare services use; a first home visit to obtain blood and urine samples; and a second home visit to perform a physical examination and to record habitual diet. For this study, we selected 6207 individuals aged $\geq 18$ years through random sampling of participants in the ENRICA study, with overrepresentation of older adults. In 2012 (after a mean of 3.5 years of follow-up), we conducted a phone interview to update information on lifestyle, diet and morbidity in a subsample of 4887 (78.7\%) participants. The socio-demographic, lifestyle and clinical characteristics were similar in subjects lost to follow-up and in those contacted. All the people who collected information at baseline and at the end of follow-up (nurses to obtain biological samples and non-health personnel for the rest of the tasks) received specific training in the study procedures.

All study participants gave their informed written consent. The Clinical Research Ethics Committee of 'La Paz' University Hospital in Madrid approved both the baseline and the follow-up study.

\section{Food consumption}

At baseline, food consumption during a typical week of the previous year was collected; the interviewers helped the study participants in reporting food intake during a typical week accounting for both seasonal and weekend food consumption. To this end, a validated computerised diet history, developed from that used in the EPIC-Spain cohort, was used ${ }^{(13,14,15)}$. Data collection was structured according to the occasions of food intake: breakfast, midmorning meal, lunch, mid-afternoon meal, dinner and snacking, which was defined as eating at any other moment. A set of pictures was used to help in estimating the portion size. Nutrients and EI were calculated using Spanish food composition tables ${ }^{(16-19)}$.

\section{Anthropometry}

Weight was recorded at baseline and at the end of follow-up by answering the following question: 'How much do you weigh without clothes or shoes on?'. Weight gain was defined as an increase of $>3 \mathrm{~kg}$ during follow-up, based on re-reported weight. We chose this cut-off point because $3 \mathrm{~kg}$ represents about $5 \%$ of body weight among normal-weight people, and it has been related to worse cardiovascular risk factors. At baseline, height and waist circumference were also measured using standardised procedures. BMI was calculated as weight $(\mathrm{kg})$ divided by squared height $\left(\mathrm{m}^{2}\right)$, and obesity was defined as a $\mathrm{BMI} \geq 30 \mathrm{~kg} / \mathrm{m}^{2}$.

\section{Potential confounders}

Study participants reported socio-demographic and lifestyle variables, including baseline age, sex, educational level and tobacco consumption as well as quitting tobacco during follow-up. Leisure time physical activity (PA) and PA at home were obtained at baseline with the questionnaire developed by the EPIC group of Spain and were expressed in metabolic equivalents (MET)-h/week ${ }^{(20)}$. PA at work was assessed asking the participants to classify their PA into one of the following categories: sedentary occupation, standing occupation, manual or heavy manual labour or unemployed ${ }^{(21)}$. Baseline information on the time spent watching TV, night sleep and daytime sleep was also obtained ${ }^{(12)}$. Dieting was assessed using the following question: 'Are you on a diet to lose weight?'. Diet quality was defined according to the Mediterranean dietary pattern estimated using the Mediterranean Diet Adherence Screener (MEDAS) ${ }^{(22)}$. This index consists of fourteen items, and twelve of them include food consumption targets: use of olive oil as the principal source of fat for cooking, consumption of $>3$ tablespoons of olive oil/d, $\geq 2$ serving/d of vegetables, $\geq 3$ servings/d of fruit, $<1$ serving/d of red meat, $<1$ serving/d of butter or margarine, $<1$ serving/d of sugar-sweetened beverages, $\geq 1$ cup/d of wine, $\geq 3$ servings/week of legumes, $\geq 3$ servings/week of fish, $<2$ servings/week of commercial pastry and $\geq 3$ servings/week of nuts. The other two items are targets for consumption habits characteristic of the Mediterranean diet in Spain: preference for white meat over red meat and $\geq 2$ times/week consumption of dishes with sofrito (a tomato sauce with garlic, onion or leeks sautéed in olive oil). A value of +1 was assigned for each target achieved. A higher MEDAS score (range 0-14) indicates better adherence to the Mediterranean diet.

Finally, individuals reported at baseline and at the end of follow-up if they had ever been diagnosed by a physician with any of the following conditions: coronary disease, stroke, chronic respiratory disease, cancer at any site, osteoarthritis/ arthritis or diabetes.

\section{Statistical analysis}

Of the 4887 participants who were contacted during follow-up, 4780 were alive at the time of the interview. Of these, twentyone were excluded for not providing valid information on diet, 451 for lacking data on weight change and sixty-five for missing values for other variables. Thus, the final analyses were performed with 4243 individuals.

Study associations were summarised with OR and their 95\% CI obtained from logistic regression, where the dependent variable was weight gain of $>3 \mathrm{~kg}$ during follow-up, and the main independent variable was baseline \%EI at each eating occasion. Percentage of EI was modelled in sex-specific quartiles, using the lowest as the reference group. Two logistic regression models were developed. Model 1 was adjusted for age, sex and total EI. Model 2 was additionally adjusted for the 
rest of potential confounders (level of education, tobacco consumption, quitting smoking during follow-up, leisure time PA, PA at home, PA at work, watching TV, night sleep, daytime sleep, BMI at baseline, dieting, MEDAS score, chronic coronary disease, stroke, chronic respiratory disease, cancer, osteoarthritis/arthritis, diabetes and incident disease during follow-up).

To assess the robustness of the results, we conducted several sensitivity analyses. Specifically, we re-ran the models using weight gain of $>5 \mathrm{~kg}$ as the dependent variable. Moreover, given that eating three or more times per day has been linked to higher weight gain ${ }^{(23)}$, we further adjusted the analyses for the number of eating occasions ( $\leq 3,4,5$ and 6$)$; individuals were considered to have skipped an eating occasion when they reported that they did not eat any food at that occasion at least once every $15 \mathrm{~d}$. In addition, as some foods that may protect from weight gain, such as vegetables and fruits, are mostly consumed at lunch and dinner, the analyses were additionally adjusted for vegetables, fruit and fibre intakes.

Finally, we assessed whether the study association varied with sex, BMI, dieting and the MEDAS score, by using likelihood ratio tests, which compared models with and without interaction terms.

Statistical significance was set at $P<0 \cdot 05$. Analyses were performed with Stata 11.2 for Windows (StataCorp LP).

\section{Results}

Lunch was the eating occasion with the highest \%EI (40\%), followed by the dinner (28\%), breakfast (16\%) and snacking (6\%). The frequency of meal skipping was very low for the main eating occasions. Men skipped the mid-afternoon meal more often than women. No substantial differences were found between men and women in the distribution of the \%EI throughout the day (Table 1).

Cut-off points for the sex-specific quartiles of \%EI at the six eating occasions are presented in Table 2 . The cut-off points for increasing quartiles of \%EI at lunch in men were $34.4,40 \cdot 8$ and $47.7 \%$, and the corresponding values in women were $33 \cdot 2,39 \cdot 4$ and $46 \cdot 1 \%$. Participants in lower quartiles of \%EI at breakfast and at lunch tended to be younger. Those in lower quartiles of $\% \mathrm{EI}$ at lunch and at dinner had a worse diet quality according to the MEDAS score. Finally, those in lower quartiles of \%EI at the main meals (breakfast, lunch and dinner) had a greater EI. Other socio-demographic, lifestyle or clinical variables showed only small differences across quartiles of \%EI (Table 2). When under-reporting status was considered, there were only small differences in \%EI at each eating occasion when comparing under-reporters and non-under-reporters (online Supplementary Table S1). On the other hand, the \%EI at each eating occasion decreased across increasing quartiles of EI at lunch, except for snacking, which remained similar throughout the lunch quartiles (data not shown).

During follow-up, $16 \cdot 3 \%$ of participants gained $>3 \mathrm{~kg}$, without substantial differences between men and women. Model 1 and 2 provided similar results for the association between \%EI throughout the day and gaining $>3 \mathrm{~kg}$. In fully adjusted analyses (model 2), compared with those in the lowest quartile of \%EI at lunch, the OR of weight gain $>3 \mathrm{~kg}$ were 0.79 (95\% CI 0.63 ,

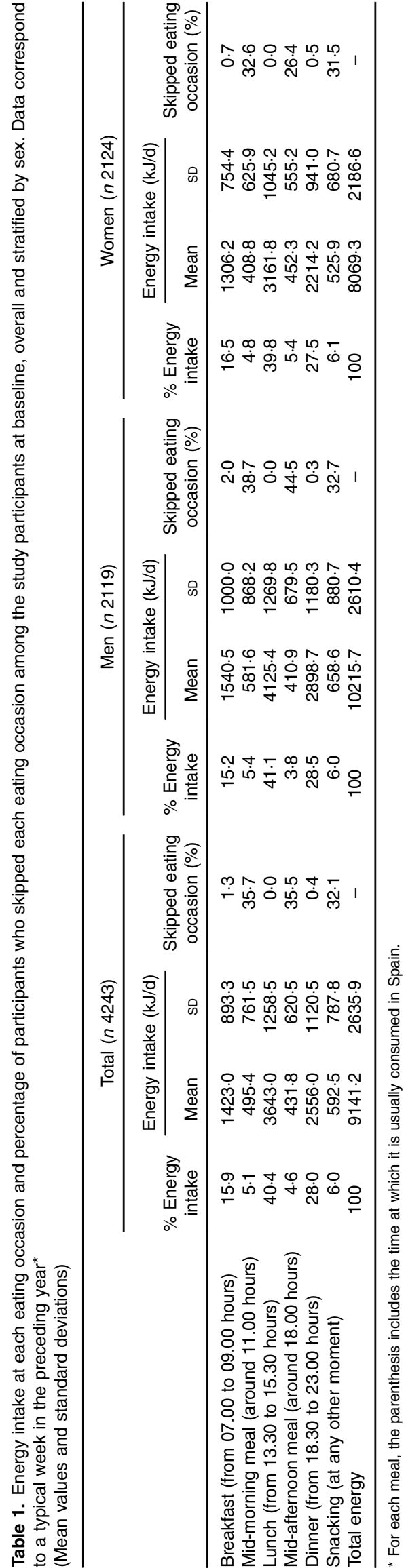


Table 2. Age-adjusted baseline characteristics of the study participants according to quartiles of percentage of energy intake (EI) in each eating occasion* (Percentages; mean values; $n$ 4243)

\begin{tabular}{|c|c|c|c|c|c|c|c|c|c|c|c|c|}
\hline & \multicolumn{2}{|c|}{$\%$ El at breakfast } & \multicolumn{2}{|c|}{$\% \mathrm{El}$ at mid-morning meal } & \multicolumn{2}{|c|}{$\%$ El at lunch } & \multicolumn{2}{|c|}{$\%$ El at mid-afternoon meal } & \multicolumn{2}{|c|}{$\%$ El at dinner } & \multicolumn{2}{|c|}{$\%$ El at snacking } \\
\hline & Q1 & Q4 & Q1 & Q4 & Q1 & Q4 & Q1 & Q4 & Q1 & Q4 & Q1 & Q4 \\
\hline Sex (\% of women) & $50 \cdot 4$ & 49.9 & 45.5 & $53 \cdot 0^{* * *}$ & 50.4 & $49 \cdot 7$ & $37 \cdot 2$ & $57 \cdot 6^{\star \star \star}$ & $50 \cdot 0$ & $50 \cdot 1$ & $48 \cdot 8$ & 51.0 \\
\hline Age (years) (mean) & $51 \cdot 1$ & $55 \cdot 7^{\star \star \star}$ & 55.7 & $49 \cdot 4^{\star \star \star}$ & 49.7 & $51 \cdot 4^{\star \star \star}$ & 53.9 & $51 \cdot 2^{\star \star}$ & 54.0 & 53.3 & $56 \cdot 7$ & $48 \cdot 4^{\star \star \star}$ \\
\hline \multicolumn{13}{|l|}{ Level of education (\%) } \\
\hline Primary or less & 33.9 & $29 \cdot 4$ & $31 \cdot 6$ & $31 \cdot 0$ & 28.4 & 31.2 & $26 \cdot 6$ & $32 \cdot 4$ & 29.8 & $30 \cdot 3$ & $31 \cdot 7$ & $29 \cdot 0$ \\
\hline Secondary & 40.5 & 37.9 & 40.5 & 39.8 & 38.3 & 39.9 & 40.4 & 41.2 & 39.2 & 37.5 & 37.9 & $41 \cdot 8^{\star \star *}$ \\
\hline University & $25 \cdot 7$ & $32 \cdot 6^{\star \star}$ & $27 \cdot 9$ & 29.2 & 33.2 & $28.4^{*}$ & 32.9 & $26 \cdot 0^{\star \star \star}$ & 31.0 & $30 \cdot 2$ & $30 \cdot 4$ & $29 \cdot 2$ \\
\hline \multicolumn{13}{|l|}{ Tobacco consumption (\%) } \\
\hline Non smoker & $42 \cdot 7$ & $50 \cdot 8^{\star \star \star}$ & 48.0 & $52 \cdot 6$ & $50 \cdot 2$ & $49 \cdot 3$ & $44 \cdot 7$ & $53 \cdot 6$ & 52.4 & $45 \cdot 9$ & 49.5 & $47 \cdot 2$ \\
\hline Former smoker & $27 \cdot 7$ & $29 \cdot 2$ & 28.6 & $26 \cdot 8$ & $27 \cdot 4$ & $28 \cdot 1$ & 31.9 & $25 \cdot 3^{\star \star \star}$ & $26 \cdot 7$ & $27 \cdot 6$ & $29 \cdot 0$ & $27 \cdot 1$ \\
\hline Current smoker & $29 \cdot 7$ & $20 \cdot 0$ & 23.4 & 20.5 & $22 \cdot 4$ & $26 \cdot 7$ & $23 \cdot 3$ & $21 \cdot 1$ & $20 \cdot 8$ & $26 \cdot 5^{\star \star}$ & 21.5 & $25 \cdot 7^{\star \star \star}$ \\
\hline Quitting tobacco during follow-up (\%) & 5.9 & 4.6 & 5.6 & $6 \cdot 0$ & 5.7 & 4.9 & 5.3 & 4.9 & 4.8 & $6 \cdot 8$ & 6.0 & 5.9 \\
\hline Leisure time physical activity (MET-h/week) (mean) & $25 \cdot 4$ & $28 \cdot 9^{\star \star \star}$ & $26 \cdot 9$ & $25 \cdot 4$ & 26.0 & $26 \cdot 3$ & 27.9 & $25 \cdot 9^{*}$ & $27 \cdot 3$ & $25 \cdot 4$ & $26 \cdot 8$ & $26 \cdot 3$ \\
\hline Physical activity at home (MET-h/week) (mean) & 39.5 & $38 \cdot 2$ & $35 \cdot 6$ & $39 \cdot 7^{\star \star \star}$ & 38.4 & $39 \cdot 1$ & $34 \cdot 0$ & $40 \cdot 4^{\star \star \star}$ & 37.4 & 39.7 & $39 \cdot 2$ & $38 \cdot 1$ \\
\hline \multicolumn{13}{|l|}{ Physical activity at work (\%) } \\
\hline Sedentary & 27.5 & 24.4 & 23.1 & $25 \cdot 1$ & 24.4 & $24 \cdot 3$ & $29 \cdot 1$ & $22 \cdot 2$ & $22 \cdot 7$ & 29.0 & $25 \cdot 8$ & $24 \cdot 2$ \\
\hline Standing & $38 \cdot 3$ & $35 \cdot 6$ & 35.5 & 39.7 & 37.0 & 39.8 & 34.4 & 37.6 & 38.8 & $36 \cdot 2^{* *}$ & 36.9 & 37.9 \\
\hline Manual or heavy manual labour & 4.3 & 3.8 & $4 \cdot 1$ & 5.8 & 4.7 & 3.7 & 4.4 & 4.5 & 4.5 & 4.4 & 3.6 & $4 \cdot 2$ \\
\hline Unemployed & 29.9 & $36 \cdot 3^{\star \star}$ & $37 \cdot 3$ & $29 \cdot 3^{\star \star *}$ & 33.9 & $32 \cdot 2$ & 31.9 & $35 \cdot 7^{\star \star \star}$ & 34.0 & $30 \cdot 4^{* *}$ & 33.7 & 33.6 \\
\hline Watching TV (h/week) (mean) & $15 \cdot 4$ & $14 \cdot 2^{\star \star}$ & $15 \cdot 3$ & $14 \cdot 5^{*}$ & $15 \cdot 2$ & $14 \cdot 3^{*}$ & $14 \cdot 2$ & $15 \cdot 7^{\star \star \star}$ & 14.4 & $15 \cdot 0$ & 14.24 & $15 \cdot 0^{*}$ \\
\hline Night sleep $(\mathrm{h} / \mathrm{d})$ (mean) & 6.9 & $7 \cdot 0$ & $7 \cdot 1$ & $6 \cdot 9^{\star \star \star}$ & $7 \cdot 0$ & 7.0 & $7 \cdot 0$ & $7 \cdot 0$ & 6.9 & $7 \cdot 0$ & $7 \cdot 0$ & 7.0 \\
\hline Daytime sleep (min/d) (mean) & $17 \cdot 2$ & $15 \cdot 2$ & 17.8 & $16 \cdot 8$ & $17 \cdot 7$ & $16 \cdot 5$ & $17 \cdot 7$ & 17.8 & $16 \cdot 8$ & $16 \cdot 9$ & $17 \cdot 0$ & $17 \cdot 2$ \\
\hline $\mathrm{BMI}\left(\mathrm{kg} / \mathrm{m}^{2}\right)$ (mean) & 27.4 & $26 \cdot 7^{\star \star \star}$ & $27 \cdot 2$ & $26 \cdot 9$ & $26 \cdot 7$ & $27 \cdot 4^{\star \star \star}$ & $27 \cdot 1$ & $26 \cdot 8$ & $27 \cdot 0$ & $27 \cdot 1$ & $26 \cdot 8$ & $27 \cdot 3^{\star \star \star}$ \\
\hline Dieting (\%) & $8 \cdot 2$ & 6.6 & $6 \cdot 2$ & $6 \cdot 6$ & 5.8 & $8 \cdot 1$ & 4.0 & $6 \cdot 7^{\star \star \star}$ & 7.3 & 6.9 & 7.7 & $8 \cdot 2$ \\
\hline MEDAS score (mean) & 7.0 & $6 \cdot 6^{* \star *}$ & $6 \cdot 8$ & $6 \cdot 0^{* * *}$ & 5.9 & $7 \cdot 2^{\star \star \star}$ & 6.9 & $6 \cdot 1^{\star \star *}$ & 6.6 & $6 \cdot 8^{\star \star *}$ & $6 \cdot 8$ & 6.8 \\
\hline Total energy intake (kJ/d) (mean) & 9150 & $8828^{\star \star \star}$ & 8866 & $9636^{\star \star \star}$ & 9970 & $8560^{\star \star \star}$ & 9050 & $9531^{\star \star \star}$ & 9192 & $8908^{\star \star}$ & 8385 & $9858^{\star \star \star}$ \\
\hline Total energy intake (kcal/d) (mean) & 2187 & $2110^{\star \star \star}$ & 2119 & $2303^{\star \star \star}$ & 2383 & $2046^{\star \star \star}$ & 2163 & $2278^{\star \star \star}$ & 2197 & $2129^{\star \star}$ & 2004 & $2356^{\star \star \star}$ \\
\hline Coronary disease $(\%)$ & 0.8 & 0.6 & 0.8 & 1.0 & 0.5 & 1.1 & 0.8 & 0.9 & 0.5 & 0.7 & 1.0 & 0.4 \\
\hline Stroke $(\%)$ & 0.4 & 0.2 & 0.6 & 0.6 & 0.4 & 0.7 & 0.8 & 0.6 & 0.4 & 0.9 & 0.6 & 0.2 \\
\hline Chronic respiratory disease (\%) & 6.9 & $7 \cdot 1$ & $7 \cdot 1$ & 6.5 & 7.1 & $7 \cdot 0$ & $5 \cdot 8$ & 7.5 & 7.9 & $6 \cdot 0$ & $6 \cdot 3$ & $6 \cdot 5$ \\
\hline Cancer (\%) & 1.2 & 1.3 & $1 \cdot 1$ & 1.6 & 1.4 & $1 \cdot 2$ & 1.2 & 1.4 & 0.8 & 1.2 & 1.4 & 0.4 \\
\hline Osteoarthritis/arthritis (\%) & $25 \cdot 0$ & 26.7 & $25 \cdot 5$ & $26 \cdot 1$ & 26.0 & $28 \cdot 7^{\star \star}$ & $24 \cdot 8$ & $29 \cdot 1^{\star \star}$ & 27.5 & 28.0 & $28 \cdot 1$ & 31.6 \\
\hline Diabetes (\%) & $10 \cdot 5$ & $7 \cdot 1^{\star \star}$ & $7 \cdot 0$ & $10 \cdot 6^{\star \star \star}$ & 9.3 & $8 \cdot 1$ & 7.5 & $10 \cdot 5^{\star}$ & $9 \cdot 3$ & $8 \cdot 8$ & 8.6 & 8.4 \\
\hline Incident disease during follow-up (\%) & 14.0 & $15 \cdot 4$ & 14.9 & 14.7 & 14.8 & 13.5 & $14 \cdot 2$ & $15 \cdot 4$ & 14.9 & $14 \cdot 0$ & 14.7 & 13.9 \\
\hline
\end{tabular}

Q1, quartile 1 (lowest); Q4, quartile 4 (highest); MET, metabolic equivalents; MEDAS, Mediterranean Diet Adherence Screener.

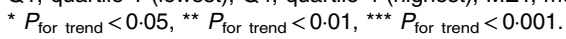

† Cut-off points for the quartiles in men: breakfast Q1: (0-29.3), Q2: (9.4-14.2), Q3: (14.3-20.1), Q4: (20.2-80.1); mid-morning meal Q1: (0), Q2: (0.1-3.4), Q3: (3.5-10.0), Q4: (10.1-62.6); lunch Q1: (0-34.4), Q2: (34.5-40.8), Q3: (40.947.7), Q4: (47.8-81.8); mid-afternoon meal Q1: (0), Q2: (0.1-3.1), Q3: (3.2-7.7), Q4: (7.8-47.3); dinner Q1: (0-22.4), Q2: (22.5-28.1), Q3: (28.2-34.2), Q4: (34.3-84.5); snacking Q1: (0), Q2: (0.1-4.5), Q3: (4.6-10.2), Q4: (10.3-47.2). Cut-off

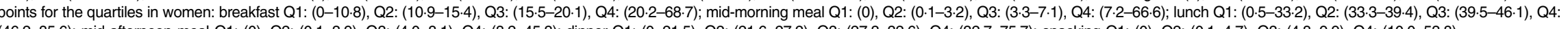

(14.2-856): 
$0.99)$ in the second quartile, $0.82(95 \% \mathrm{CI} 0.64,1.04)$ in the third quartile and 0.62 (95\% CI $0.47,0.80)$ in the highest quartile; $P_{\text {for trend }} 0.001$ (Table 3). During follow-up, $8.4 \%$ of participants gained $>5 \mathrm{~kg}$. Similar results were obtained for weight gain

Table 3. Weight gain ( $>3 \mathrm{~kg}$ ) during follow-up according to quartiles of percentage of energy intake (EI) in each eating occasion at baseline (Odds ratios and $95 \%$ confidence intervals)

\begin{tabular}{|c|c|c|c|c|}
\hline & \multicolumn{2}{|c|}{ Model $1 \dagger$} & \multicolumn{2}{|c|}{ Model 2ł } \\
\hline & OR & $95 \% \mathrm{Cl}$ & OR & $95 \% \mathrm{Cl}$ \\
\hline \multicolumn{5}{|l|}{$\%$ El at breakfast } \\
\hline Quartile 1 (lowest) & \multicolumn{2}{|c|}{ Ref. } & \multicolumn{2}{|c|}{ Ref. } \\
\hline Quartile 2 & 1.01 & $0.80,1.23$ & 1.01 & $0.79,1.27$ \\
\hline Quartile 3 & 0.83 & $0.65,1.05$ & 0.81 & $0.63,1.03$ \\
\hline Quartile 4 (highest) & $1 \cdot 11$ & $0.88,1.40$ & $1 \cdot 13$ & $0.89,1.43$ \\
\hline \multicolumn{5}{|c|}{$\%$ El at mid-morning meal } \\
\hline Quartile 1 (lowest) & \multicolumn{2}{|c|}{ Ref. } & \multicolumn{2}{|c|}{ Ref. } \\
\hline Quartile 2 & 1.00 & $0.79,1.26$ & 1.00 & $0.79,1.26$ \\
\hline Quartile 3 & 0.98 & $0.78,1.24$ & 1.00 & $0.79,1.27$ \\
\hline Quartile 4 (highest) & $1.35^{\star}$ & $1 \cdot 10,1 \cdot 71$ & 1.28 & $0.98,1.63$ \\
\hline \multicolumn{5}{|l|}{$\%$ El at lunch } \\
\hline Quartile 1 (lowest) & \multicolumn{2}{|c|}{ Ref. } & \multicolumn{2}{|c|}{ Ref. } \\
\hline Quartile 2 & $0.77^{*}$ & $0.62,0.96$ & $0.79^{*}$ & $0.63,0.99$ \\
\hline Quartile 3 & $0.76^{*}$ & $0.61,0.95$ & 0.82 & $0.64,1.04$ \\
\hline Quartile 4 (highest) & $0.57^{\star \star \star}$ & $0.45,0.73$ & $0 \cdot 62^{\star \star \star}$ & $0.47,0.80$ \\
\hline \multicolumn{5}{|c|}{$\%$ El at mid-afternoon meal } \\
\hline Quartile 1 (lowest) & \multicolumn{2}{|c|}{ Ref. } & \multicolumn{2}{|c|}{ Ref. } \\
\hline Quartile 2 & 1.02 & $0.81,1.28$ & 0.96 & $0 \cdot 76,1 \cdot 21$ \\
\hline Quartile 3 & 1.05 & $0.84,1.32$ & 0.95 & $0.75,1.20$ \\
\hline Quartile 4 (highest) & 1.09 & $0.86,1.36$ & 0.94 & $0.75,1.19$ \\
\hline \multicolumn{5}{|l|}{$\%$ El at dinner } \\
\hline Quartile 1 (lowest) & \multicolumn{2}{|c|}{ Ref. } & \multicolumn{2}{|c|}{ Ref. } \\
\hline Quartile 2 & 1.02 & $0.81,1.29$ & 1.01 & $0.80,1.27$ \\
\hline Quartile 3 & 0.96 & $0.76,1.22$ & 0.96 & $0.76,1.22$ \\
\hline Quartile 4 (highest) & 1.01 & $0.80,1.27$ & 1.02 & $0.81,1.30$ \\
\hline \multicolumn{5}{|l|}{$\%$ El at snacking } \\
\hline Quartile 1 (lowest) & \multicolumn{2}{|c|}{ Ref. } & \multicolumn{2}{|c|}{ Ref. } \\
\hline Quartile 2 & 0.88 & $0.70,1.11$ & 0.88 & $0.70,1.11$ \\
\hline Quartile 3 & 1.05 & $0.84,1.31$ & 1.06 & $0.84,1.33$ \\
\hline Quartile 4 (highest) & 0.94 & $0.74,1 \cdot 18$ & 0.93 & $0.73,1.18$ \\
\hline
\end{tabular}

Ref., referent value; MET, metabolic equivalents.

${ }^{\star} P<0.05,{ }^{\star \star *} P<0.001$.

† Model 1: adjusted for sex, age (18-29, 30-44, 45-64, $\geq 65$ years) and total El.

$\ddagger$ Model 2: adjusted as model 1 plus for level of education (primary or less, secondary, university), tobacco consumption (never, former and current smoker), quitting smoking during follow-up (no/yes), leisure time physical activity in MET-h/week (quartiles), physical activity at home in MET-h/week (quartiles), physical activity at work (sedentary, standing, manual or heavy manual labour, unemployed), watching TV in $\mathrm{h} / \mathrm{d}$ (quartiles), night sleep in $\mathrm{h} / \mathrm{d}$ (quartiles), daytime sleep in $\mathrm{min} / \mathrm{d}$ (quartiles), BMI at baseline (quartiles), dieting (no/yes), Mediterranean Diet Adherence Screener score, chronic coronary disease (no/yes), stroke (no/yes), chronic respiratory disease (no/yes), cancer (no/yes), osteoarthritis/ arthritis (no/yes), diabetes (no/yes) and incident disease during follow-up (no/yes).

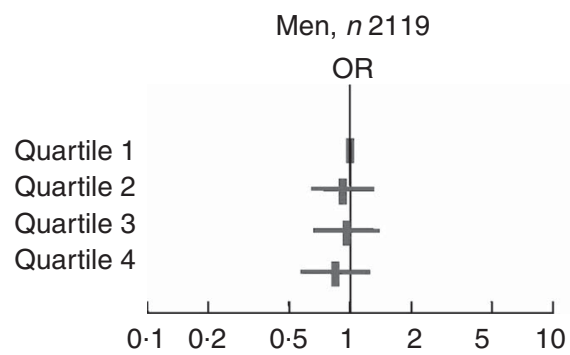

$>5 \mathrm{~kg}$; the corresponding figures for the quartiles of $\% \mathrm{EI}$ at lunch were 0.71 (95\% CI 0.52, 0.96), 0.75 (95\% CI 0.54, 1.03) and 0.69 (95\% CI $0.50,0.97) ; P_{\text {for trend }} 0.047$. Further adjustment for the number of eating occasions, as well as for vegetable, fruit and fibre intakes, did not materially change the results. In analyses stratified by sex, the results were in the same direction, although the association between \%EI at lunch and lower risk of weight gain remained statistically significant only in women; $P_{\text {for interaction }} 0.43$ (Fig. 1). After stratification by BMI, the association was stronger in those with overweight or obesity, although again the interaction did not reach statistical significance; $P_{\text {for interaction }} 0.72$. Finally, the association remained similar in strata defined by dieting and the MEDAS score (Fig. 2).

A higher \%EI at lunch was associated with a lower \%EI at the rest of eating occasions, and with an increased frequency of skipped mid-morning and mid-afternoon meals and snacking; moreover, the \%EI from carbohydrates decreased, whereas the \%EI from lipids and alcohol increased (Table 4). No association was found between the \%EI at the rest of the eating occasions and weight gain (Table 3).

\section{Discussion}

In this adult population of a Mediterranean country, where lunch is the main meal of the day, a higher \%EI at lunch was associated with a lower risk of weight gain. This association was stronger in women and in those with overweight or obesity. Those with higher \%EI at lunch also had higher intake of fat but lower intake of carbohydrates. Finally, we did not find an association between \%EI at dinner or at any other eating occasion and weight gain.

Our results are consistent with those from a cross-sectional analysis including 239 subjects - the 'Los Angeles Energetics Study'. In this study, participants with $\geq 33 \%$ of their EI at 12.00 hours were less likely to be overweight or obese. However, having $\geq 33 \%$ of EI at dinner was associated with a greater frequency of weight gain, although the association lost statistical significance when the analysis was restricted to true reporters (based on doubly labelled water to measure EI) ${ }^{(24)}$.

Our results are in line with pioneering studies of the association between chronobiology and chronic diseases. A study among seventy women found that the presence of chronodisruption was related to obesity and the metabolic syndrome $^{(8)}$. Moreover, in another study, obese women had lower sleep efficiency, ate more quickly and spent more time

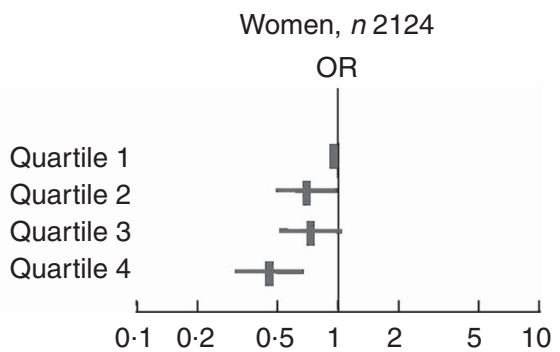

Fig. 1. Association between the quartiles of percentage of energy intake at lunch and $>3 \mathrm{~kg}$ weight gain stratified by sex. Odds ratios and their $95 \%$ confidence interval are presented. Analyses were adjusted as in model 2. 


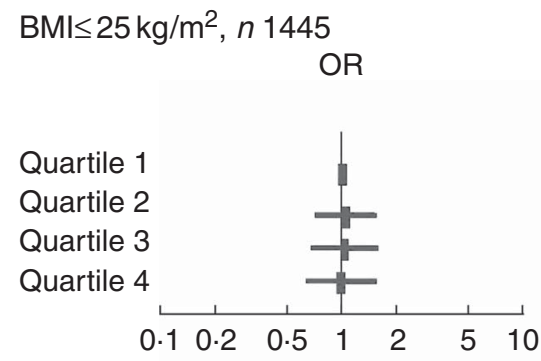

Dieting, $n 308$

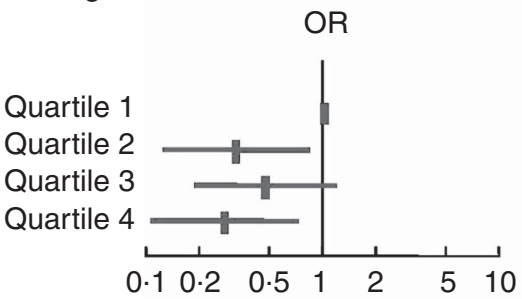

MEDAS $\geq 9, n 743$

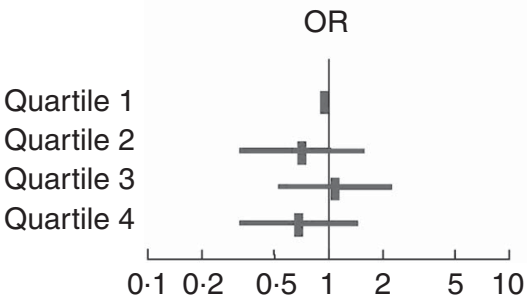

$\mathrm{BMl}>25 \mathrm{~kg} / \mathrm{m}^{2}, n 2798$

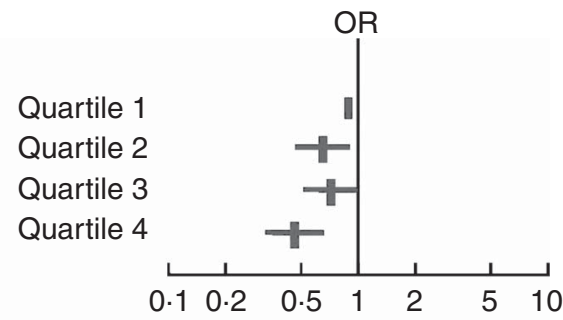

No dieting, $n 3931$

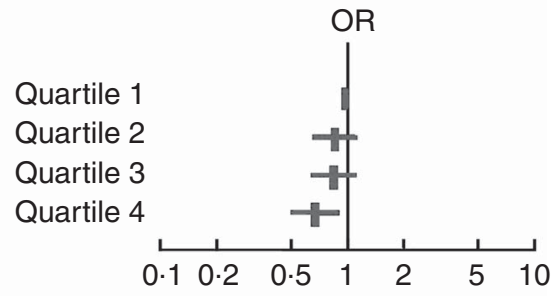

MEDAS $<9, n 3500$

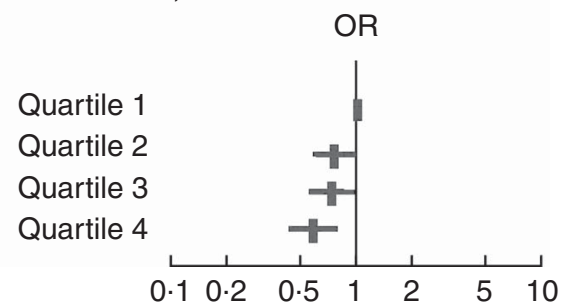

Fig. 2. Association between quartiles of percentage of energy intake at lunch and $>3 \mathrm{~kg}$ weight gain stratified by BMI, dieting and Mediterranean Diet Adherence Screener (MEDAS) score. Odds ratios and their $95 \%$ confidence interval are presented. Analyses were adjusted as in model 2.

Table 4. Distribution of percentage of energy intake (EI) at several eating occasions, frequency of skipped eating occasions and \%El from macronutrients and alcohol, according to quartiles $(\mathrm{Q})$ of $\% \mathrm{El}$ at lunch* (Mean values; percentages)

\begin{tabular}{|c|c|c|c|c|}
\hline & \multicolumn{4}{|c|}{$\%$ El at lunch } \\
\hline & Q1 & Q2 & Q3 & Q4 \\
\hline \multicolumn{5}{|l|}{$\%$ EI } \\
\hline Breakfast (mean) & $18 \cdot 3$ & $17 \cdot 0$ & $15 \cdot 4$ & $12 \cdot 8$ \\
\hline Mid-morning meal (mean) & 8.9 & $5 \cdot 1$ & 3.6 & $2 \cdot 7$ \\
\hline Lunch (mean) & $28 \cdot 1$ & $37 \cdot 1$ & 43.4 & $53 \cdot 3$ \\
\hline Mid-afternoon meal (mean) & $7 \cdot 2$ & 4.8 & 3.9 & 2.5 \\
\hline Dinner (mean) & $29 \cdot 0$ & $29 \cdot 3$ & 28.5 & $25 \cdot 1$ \\
\hline Snacking (mean) & 8.5 & $6 \cdot 7$ & $5 \cdot 3$ & 3.6 \\
\hline \multicolumn{5}{|c|}{ Frequency of skipped eating occasion } \\
\hline Breakfast (\%) & 1.4 & 0.4 & 1.1 & $2 \cdot 7$ \\
\hline Mid-morning meal (\%) & 24.5 & 31.0 & $40 \cdot 0$ & $46 \cdot 9$ \\
\hline Mid-afternoon meal (\%) & 24.5 & 29.9 & $37 \cdot 1$ & $50 \cdot 4$ \\
\hline Dinner (\%) & 0.3 & 0.0 & 0.1 & $1 \cdot 3$ \\
\hline Snacking (\%) & $24 \cdot 7$ & $27 \cdot 0$ & $31 \cdot 7$ & 44.5 \\
\hline \multicolumn{5}{|c|}{$\%$ El from macronutrients and alcohol } \\
\hline Proteins (mean) & $20 \cdot 6$ & $21 \cdot 0$ & $20 \cdot 9$ & $20 \cdot 6$ \\
\hline Lipids (mean) & $35 \cdot 8$ & $36 \cdot 3$ & $36 \cdot 9$ & 38.5 \\
\hline Carbohydrates (mean) & 41.0 & 39.7 & $38 \cdot 2$ & $36 \cdot 4$ \\
\hline Alcohol (mean) & 2.5 & 2.9 & 3.9 & 4.5 \\
\hline
\end{tabular}

* All values were age-adjusted.

eating and sleeping during daytime than women with normal weight. Moreover, a higher EI in obese women was related to a higher frequency of snacking at night ${ }^{(9)}$. Finally, a common type 2 diabetes risk variant in $M T N R 1 B$ has been linked to a worse effect of melatonin on glucose tolerance ${ }^{(10)}$.

Most studies on the health effects of the distribution of EI during the day have focused on night-eaters, skipping breakfast and on the number of eating occasions. In a study with 117 healthy non-diabetic Pima Indians and forty-five white participants, 36\% were night-eaters. After 6 months of follow-up, night-eaters gained more weight than non-night-eaters ${ }^{(25)}$. In another prospective study in Copenhagen with 2111 individuals, night eating was not associated with subsequent weight gain, except among obese women who further increased their weight ${ }^{(26)}$. Unfortunately, in our study, night eating was included as part of snacking, and therefore we cannot distinguish night-eaters from people who have a snack at any other moment. However, given that snacking represented only $6 \%$ of EI, and that snacking was not associated with weight gain, it is unlikely that night-time snacking could have influenced weight gain.

With regard to breakfast, most data on its weight effects derive from cross-sectional and a few longitudinal studies, which do not provide definite causal evidence ${ }^{(27)}$; however, most data suggest that having breakfast on almost all or all of the days is associated with a reduced frequency of overweight or obesity ${ }^{(28,29)}$. One possible mechanism of this association is that breakfast skippers overcompensate EI by consuming higher amounts of high energy-dense food later in the day due to a poor appetite control ${ }^{(27)}$. In our study, only $1.3 \%$ of 
individuals skipped breakfast. Thus, it is unlikely to represent an important risk factor for weight gain in our population.

There is also uncertain evidence about the effect of the number of eating occasions on body weight. It has been suggested that a high number of meals and snacks may be linked to a higher total EI, and that eating more than three meals a day may be associated with overweight and obesity ${ }^{(23)}$. A reduction in satiety response to dietary fibre has been postulated as a possible mechanism ${ }^{(23)}$. On the other hand, reducing the number of eating occasions has been related to a better lipid profile in obese individuals ${ }^{(30)}$. In our study, the main results also held after additional adjustment for the number of eating occasions, and no association was found between the number of eating occasions and weight gain (data not shown).

There is also recent interest on whether the timing of food intake may affect weight regulation. In one study with animals, an unusual food timing was associated with weight gain ${ }^{(5)}$. Moreover, in animals, results from another study suggest that timed feeding $v$. ad libitum feeding could prevent obesity and even reverse the harmful effects of a high-fat diet ${ }^{(31)}$. In addition, experimental studies on circadian misalignment in humans (e.g. jet-lag and night-shift work) have shown decreased leptin concentrations, increased glucose and insulin levels, reversed daily cortisol rhythm and increased mean arterial pressure $^{(32)}$. Moreover, there is some evidence that light at night increases body mass by shifting the time of food intake $^{(3)}$ and that short sleep duration or sleep deprivation are related to obesity ${ }^{(33-35)}$. Finally, the timing of dessert consumption can also be of relevance. In a randomised, crossover study with children aged 2-5 years, serving the dessert with the main course reduced total EI, regardless of the portion size of the main course ${ }^{(36)}$.

A large part of the biological activity shows a circadian rhythm, and it has been suggested that between 10 and $30 \%$ of the human genome is under the circadian clock control ${ }^{(37)}$. There is evidence of the existence of a central circadian clock that synchronises peripheral circadian clocks (e.g. in the liver, intestine, pancreas and peripheral fat tissue), and that these peripheral clocks are sensitive to food timing. Indeed, timing of food along with sleeping and light/ dark conditions ${ }^{(3)}$ are considered natural synchronisers of peripheral and central clocks ${ }^{(38)}$. Of particular relevance is the effect of food timing on peripheral fat because many genes expressed in adipose tissue follow a circadian rhythm, which appears to be critical in accumulating or mobilising fat ${ }^{(39)}$. In addition, hormonal secretion and hunger are under circadian control ${ }^{(38,40)}$. Thus, a significant EI at the 'wrong time' of the day may alter peripheral circadian clocks, resulting in dysregulation of metabolism and weight ${ }^{(41)}$. However, despite substantial research on the effect of food timing on weight regulation $^{(42)}$, we still lack a complete understanding of its mechanisms. These may nonetheless include changes in satiety ${ }^{(24)}$, decreased insulin sensitivity and glucose tolerance ${ }^{(6)}$, changes in the circadian regulation of adipose tissue ${ }^{(39)}$ and alterations in the circadian rhythm of cortisol and other hormones ${ }^{(4)}$.

The main strength of this study is that participants were selected from the general population. Moreover, the analyses were adjusted for an important number of potential confounders including total EI, time devoted to sleep at night and during daytime, diet quality and many other lifestyle factors.
The main limitation is that weight was self-reported. However, at baseline, we obtained both measured and self-reported weight and they showed high correlation ( $r$ 0.98), with a mean under-reporting of $0.74 \mathrm{~kg}$. In addition, there was substantial cohort attrition, particularly because of individuals with missing data on weight change; however, it is difficult to know its possible effect on the study results. However, we did not find important differences in socio-demographic, lifestyle and clinical characteristics between subjects lost to follow-up and those contacted. Another limitation could be under-reporting of EI, but there is no reason to suggest that it was different across eating occasions. Moreover, although food consumption data were collected with a valid diet history, EI throughout the day has not been validated. Finally, the results may not apply to countries where lunch is not the main meal, and therefore specific studies are needed in such populations.

In conclusion, a higher \%EI at lunch, the main meal of the day in Spain, was associated with a lower risk of weight gain. If this finding is confirmed in future studies, it may help improve the effectiveness of weight-control interventions ${ }^{(43)}$, by emphasising the appropriate distribution of EI throughout the day.

\section{Acknowledgements}

Baseline data collection of the ENRICA cohort was funded by Sanofi-Aventis. Data collection during follow-up was funded by Fondo de Investigaciones Sanitarias (FIS) grant no. PI11/0137, FIS grant no. PI12/1166 and FIS grant no. P13/0288 (State Secretary of $\mathrm{R}+\mathrm{D}$ and Fondo Europeo de DEsarrollo Regional (FEDER)/ Fondo Social Europeo (FSE). R. F. P.-T. received a grant from the National Government of Ecuador through the National Institution of Higher Education, Science, Technology and Innovation. The study funders had no role in the study design, in the collection, analysis and interpretation of data, as well as in the decision to submit the manuscript for publication. The authors have sole responsibility for the manuscript content.

P. G.-C. and Y. H. are the study's guarantors, were responsible for the concept of the study and drafted the manuscript; E. L.-G., E. G.-E. and R. F. P.-T. analysed the data; F. R.-A. provided input on the study design and drafted the manuscript; and all the authors contributed to the interpretation of results and writing of the manuscript.

The authors declare that there are no conflicts of interest.

\section{Supplementary material}

For supplementary material/s referred to in this article, please visit http://dx.doi.org/doi:10.1017/S0007114516000891

\section{References}

1. Prentice AM (1995) Are all calories equal? In Weight Control, pp. 8-33. The Netherlands: Springer Netherlands.

2. Shea SA (2012) Obesity and pharmacologic control of the body clock. $N$ Engl J Med 367, 175-178.

3. Fonken LK, Workman JL, Walton JC, et al. (2010) Light at night increases body mass by shifting the time of food intake. Proc Natl Acad Sci U S A 107, 18664-18669.

4. Garaulet M \& Gomez-Abellan P (2014) Timing of food intake and obesity: a novel association. Physiol Behav 134, 44-50. 
5. Arble DM, Bass J, Laposky AD, et al. (2009) Circadian timing of food intake contributes to weight gain. Obesity (Silver Spring) 17, 2100-2102.

6. Jakubowicz D, Barnea M, Wainstein J, et al. (2013) High caloric intake at breakfast vs. dinner differentially influences weight loss of overweight and obese women. Obesity (Silver Spring) 21, 2504-2512.

7. Garaulet M, Gomez-Abellan P, Alburquerque-Bejar JJ, et al. (2013) Timing of food intake predicts weight loss effectiveness. Int J Obes (Lond) 37, 604-611.

8. Corbalan-Tutau MD, Gomez-Abellan P, Madrid JA, et al. (2015) Toward a chronobiological characterization of obesity and metabolic syndrome in clinical practice. Clin Nutr 34, 477-483.

9. Corbalan-Tutau MD, Madrid JA \& Garaulet M (2012) Timing and duration of sleep and meals in obese and normal weight women. Association with increase blood pressure. Appetite 59, 9-16.

10. Garaulet M, Gomez-Abellan P, Rubio-Sastre P, et al. (2015) Common type 2 diabetes risk variant in MTNR1B worsens the deleterious effect of melatonin on glucose tolerance in humans. Metabolism 64, 1650-1657.

11. Rodriguez-Artalejo F, Graciani A, Guallar-Castillon $\mathrm{P}$, et al. (2011) Rationale and Methods of the Study on Nutrition and Cardiovascular Risk in Spain (ENRICA). Rev Esp Cardiol (Engl Ed) 64, 876-882.

12. Guallar-Castillon P, Bayan-Bravo A, Leon-Munoz LM, et al. (2014) The association of major patterns of physical activity, sedentary behavior and sleep with health-related quality of life: a cohort study. Prev Med 67, 248-254.

13. EPIC Group of Spain (1997) Relative validity and reproducibility of a diet history questionnaire in Spain. I. Foods. European Prospective Investigation into Cancer and Nutrition. Int J Epidemiol 26, Suppl. 1, S91-S99.

14. EPIC Group of Spain (1997) Relative validity and reproducibility of a diet history questionnaire in Spain. II. Nutrients. EPIC Group of Spain. European Prospective Investigation into Cancer and Nutrition. Int J Epidemiol 26, Suppl. 1, S100-S109.

15. Guallar-Castillon P, Sagardui-Villamor J, Balboa-Castillo T, et al. (2014) Validity and reproducibility of a Spanish dietary history. PLOS ONE 9, e86074.

16. Ortega Anta RM, Lopez Sobaler AM, Carvajales PA, et al. (2007) Programa DIAL. http://wwwalceingenieria net/ nutricionhtm (accessed July 2014).

17. Jimenez Cruz A, Cervera Ral P \& Barcardí Gascón M (1990) Tabla de Composición de Alimentos (Food Composition Table), 1st ed. Barcelona: Wander-Sandoz Nutrition.

18. Farran A, Zamora R \& Cervera P (2004) Tablas de Composición de Alimentos del Centre d'Ensenyament Superior de Nutrició i Dietètica (CESNID) (Food Composition Tables from the Centre d'Ensenyament Superior de Nutrició i Dietètica). Barcelona: MCGraw-Hill/Interamericana de España, S.A.U. Edicions Universitat de Barcelona.

19. Moreiras O, Carvajal A, Cabrera L, et al. (2007) Tablas de Composición de Alimentos (Food Composition Tables), 11th ed. Madrid: Ediciones Pirámide.

20. Pols MA, Peeters PH, Ocke MC, et al. (1997) Estimation of reproducibility and relative validity of the questions included in the EPIC Physical Activity Questionnaire. Int J Epidemiol 26, Suppl. 1, S181-S189.

21. Haftenberger M, Schuit AJ, Tormo MJ, et al. (2002) Physical activity of subjects aged 50-64 years involved in the European Prospective Investigation into Cancer and Nutrition (EPIC). Public Health Nutr 5, 1163-1176.

22. Schroder H, Fito M, Estruch R, et al. (2011) A short screener is valid for assessing Mediterranean diet adherence among older Spanish men and women. J Nutr 141, 1140-1145.
23. Howarth NC, Huang TT, Roberts SB, et al. (2007) Eating patterns and dietary composition in relation to BMI in younger and older adults. Int J Obes (Lond) 31, 675-684.

24. Wang JB, Patterson RE, Ang A, et al. (2014) Timing of energy intake during the day is associated with the risk of obesity in adults. J Hum Nutr Diet 27, Suppl. 2, 255-262.

25. Gluck ME, Venti CA, Salbe AD, et al. (2008) Nighttime eating: commonly observed and related to weight gain in an inpatient food intake study. Am J Clin Nutr 88, 900-905.

26. Andersen GS, Stunkard AJ, Sorensen TI, et al. (2004) Night eating and weight change in middle-aged men and women. Int J Obes Relat Metab Disord 28, 1338-1343.

27. Timlin MT \& Pereira MA (2007) Breakfast frequency and quality in the etiology of adult obesity and chronic diseases. Nutr Rev 65, 268-281.

28. Szajewska H \& Ruszczynski M (2010) Systematic review demonstrating that breakfast consumption influences body weight outcomes in children and adolescents in Europe. Crit Rev Food Sci Nutr 50, 113-119.

29. Horikawa C, Kodama S, Yachi Y, et al. (2011) Skipping breakfast and prevalence of overweight and obesity in Asian and Pacific regions: a meta-analysis. Prev Med 53, 260-267.

30. Kulovitz MG, Kravitz LR, Mermier C, et al. (2014) Potential role of meal frequency as a strategy for weight loss and health in overweight or obese adults. Nutrition 30, 386-392.

31. Sherman H, Genzer Y, Cohen R, et al. (2012) Timed high-fat diet resets circadian metabolism and prevents obesity. FASEB J 26, 3493-3502.

32. Scheer FA, Hilton MF, Mantzoros CS, et al. (2009) Adverse metabolic and cardiovascular consequences of circadian misalignment. Proc Natl Acad Sci U S A 106, 4453-4458.

33. Taheri S, Lin L, Austin D, et al. (2004) Short sleep duration is associated with reduced leptin, elevated ghrelin, and increased body mass index. PLOS Med 1, e62.

34. McNeil J, Drapeau V, Gallant AR, et al. (2013) Short sleep duration is associated with a lower mean satiety quotient in overweight and obese men. Eur J Clin Nutr 67, 1328-1330.

35. Parvaneh K, Poh BK, Hajifaraji M, et al. (2014) Sleep deprivation is related to obesity and low intake of energy and carbohydrates among working Iranian adults: a cross sectional study. Asia Pac J Clin Nutr 23, 84-90.

36. Huss LR, Laurentz S, Fisher JO, et al. (2013) Timing of serving dessert but not portion size affects young children's intake at lunchtime. Appetite 68, 158-163.

37. Garaulet M \& Gomez-Abellan P (2013) Chronobiology and obesity. Nutr Hosp 28, Suppl. 5, 114-120.

38. Challet E (2013) Circadian clocks, food intake, and metabolism. Prog Mol Biol Transl Sci 119, 105-135.

39. Garaulet M, Ordovas JM, Gomez-Abellan P, et al. (2011) An approximation to the temporal order in endogenous circadian rhythms of genes implicated in human adipose tissue metabolism. J Cell Physiol 226, 2075-2080.

40. Wuorinen EC \& Borer KT (2013) Circadian and ultradian components of hunger in human non-homeostatic meal-tomeal eating. Physiol Behav 122, 8-16.

41. Garaulet M \& Madrid JA (2010) Chronobiological aspects of nutrition, metabolic syndrome and obesity. Adv Drug Deliv Rev 62, 967-978.

42. Bandin C, Scheer FA, Luque AJ, et al. (2014) Meal timing affects glucose tolerance, substrate oxidation and circadianrelated variables: a randomized, crossover trial. Int $J$ Obes (Lond) 39, 828-833.

43. Bandin C, Martinez-Nicolas A, Ordovas JM, et al. (2013) Circadian rhythmicity as a predictor of weight-loss effectiveness. Int J Obes (Lond) 38, 1083-1088. 